\title{
MEIO AMBIENTE E DIREITO DAS CIDADES: uma interrelação necessária para o desenvolvimento de uma urbanização sustentável
}

\author{
Fátima Fagundes Barasuol Hammarströn ${ }^{1}$; \\ Daniel Rubens Cenci ${ }^{2}$
}

\begin{abstract}
RESUMO
Atualmente, diante do contexto histórico, cultural e econômico por que passa a sociedade moderna, especialmente no aspecto voltado ao desenvolvimento urbano é imprescindível um olhar interdisciplinar e crítico sobre o direito ao meio ambiente ecologicamente equilibrado e direito à cidades sustentáveis, o que leva a pensar na garantia de um desenvolvimento sustentável como sendo uma das preocupações de pesquisadores, governos, legisladores, inclusive no âmbito internacional. Não basta a conscientização das problemáticas que envolvem os direitos humanos e o meio ambiente urbano, como parte deste, mas é necessário (re)pensar, (re)significar e mais precisamente agir, das mais variadas formas, individual e coletivamente, através de medidas que perpassam pela efetivação de uma (re)construção de novas concepções e modalidades de cidades.
\end{abstract}

PALAVRAS-CHAVE: Desenvolvimento Sustentável. Ambiente Urbano.

\section{INTRODUÇÃO}

A evolução da sociedade com suas incalculáveis transformações e o estrondoso desenvolvimento urbano de forma desordenada, bem como os riscos que tais situações trouxeram aos recursos naturais e a própria sobrevivência das espécies, obrigou a pensar o meio ambiente em toda a sua amplitude, inclusive na questão urbana. Assim, o desenvolvimento de ações concretas de preservação e de uma urbanização ordenada e planejada de forma que as cidades passem a ser desenvolvidas como um todo, sem fragmentações e divisões entre o centro e a periferia, é exclusiva forma de evitar os riscos ambientais que atualmente se apresentam, já que este é um direito que se perpassa as futuras gerações.

Tais preocupações e constatações levaram a construção deste texto, o qual traz uma breve evolução dos direitos humanos, passando pelas conceitualizações clássicas, até chegar a teoria crítica, o que é imprescindível para se entender a amplitude destes no contexto de garantias fundamentais dos seres, fazendo um interligação destes com o

\footnotetext{
${ }^{1}$ Mestranda em Desenvolvimento pela Universidade Regional do Noroeste do Rio Grande do Sul UNIJUÍ e bolsista CAPES; fatima.advocacia@ hotmail.com

2 Professor Doutor do DCJS - Departamento de Ciências Jurídicas e Sociais da Universidade Regional do Noroeste do Rio Grande do Sul - UNIJUÍ, Coordenador do Projeto de Pesquisa "O direito ambiental no contexto da sociedade de risco: em busca da justiça ambiental e da sustentabilidade". danielr@unijui.edu.br
} 
III SEMINÁRII ECDLOGIA

POLÍTICA

meio ambiente em sua amplitude. São apresentados alguns dos cenários atuais que levam a verificação não somente da situação preocupante que encontra-se o meio ambiente, especialmente o meio ambiente urbano, como também da extrema necessidade de ações concretas, que ultrapassem a simples conceituar e pensar e concluindo com uma discussão sobre o desenvolvimento sustentável das cidades, especialmente fundamentada nas obras de Henri Lefebvre.

\section{Meio ambiente saudável e cidade sustentável: interligados pelo princípio da dignidade da pessoa humana}

O Estatuto da Cidade, aprovado em 2001, após 11 anos de debates e negociações, traz como princípios da política urbana uma relação direta destes com os princípios da dignidade da pessoa humana, estando aqui diretamente incluídos os direitos humanos, fazendo com que o direito a cidade sustentável passa a ser considerado um direito fundamental e, portanto, diretamente vinculado ao desenvolvimento sustentável e, conseqüentemente ao direito ao desenvolvimento urbano.

De acordo com Sarmento (2002, p. 60) "A norma que estabelece o direito às cidades sustentáveis tem seu fundamento nos princípios da dignidade da pessoa humana e da solidariedade preconizados pela Constituição da República (artigos $1^{\circ}$, III, e $3^{\circ}$, I), pelo que é importante lembrar que o respeito a dignidade da pessoa humana é o que legitima a ordem estatal e comunitária, construindo, a um só tempo, pressuposto e objetivo da democracia."

Contudo, antes de discutir esta interrelação entre o ao meio ambiente equilibrado e sadio e o direito à cidade é imprescindível, fazer uma breve apreciação da crise em que se encontra o ambiente urbano e suas principais causas, uma vez que não se tratam de problemas locais e isolados, mas que envolvem questões globais, assim como toda a crise ambiental.

$\mathrm{O}$ aumento populacional, especialmente na zona urbana, associado às desigualdades sociais é ao mesmo tempo causa e consequência dos problemas ambientais. Esse aumento populacional teve seu marco inicial com a Revolução Industrial, sendo que, conforme Meadows (2007), o pico de crescimento ocorreu entre 
aos o meio dos anos 90 e início dos anos 2000, tendo em 2001 apresentado uma taxa de crescimento populacional mundial de 1,3\% ao ano, o que corresponde ao dobro do que ocorria no início dos anos 90. Tal crescimento, na forma como vem ocorrendo, ao invés de eliminar a pobreza, acabam por perpetuá-la, aumentando a disparidade entre ricos e pobres. De acordo com o mesmo autor, “[...] no sistema econômico vigente, o crescimento geralmente se dá nos países que já são ricos e flui desproporcionalmente para as pessoas mais ricas desses países. [...] décadas de crescimento têm sistematicamente aumentado as diferenças entre ricos e pobres. Segundo o Programa das Nações Unidas para o Desenvolvimento, em 1960, $20 \%$ da população mundial que vivia nos países mais ricos possuía uma renda per capita 30 vezes maior do que os $20 \%$ que viviam nos países mais pobres. Por volta de 1995 a relação entre a renda média dos $20 \%$ mais ricos e dos $20 \%$ mais pobres tinha passado de 30:1 para 82:1.” (2007, p. 42)

Outro dado importante trazido por Davis (2006) é de que as cidades têm absorvido quase dois terços do crescimento populacional global, sendo que a previsão é de que no ano de 2020, a população urbana chegue a 10 bilhões de habitantes, o que significa que $95 \%$ do aumento populacional ocorrerá nas cidades. Contudo, esse aumento estrondoso da população urbana levará a uma desigualdade cada vez maior, visto que a forma de distribuição dessas pessoas não obedece a critérios organizacionais e os grandes aglomerados, ensejares das maiores favelas, que nada mais são do que cidades informais (Sirkis, 2003), acabam por se formarem sem que sejam percebidos especialmente nos países menos desenvolvidos, onde 78,2\% da população urbana está nas favelas em contrapartida a $19 \%$ que se encontram nas mesmas nos países desenvolvidos.

Tudo isso gira em torno de uma busca incessante pelo trabalho, o que leva as pessoas, que muitas vezes estão no meio rural, a criarem a ideia imaginária de uma qualidade melhor de vida nas cidades, onde o trabalho é mais diversificado, o que não passa de um lego engano, pois acabam por transformarem-se em meros instrumentos de produção.

A industrialização acabou por gerar a exploração do homem pelo próprio homem, onde a forma de urbanização que passou a se desenvolver desconstituiu a personalidade humana fazendo com os indivíduos passassem a serem meros reprodutores de uma concepção capitalista onde o interesse econômico e a busca pela 
acumulação de capital se sobrepôs ao interesse social, fazendo que surgisse um distanciamento e uma dissolução das relações sociais, o que levou facilidade de alienação e, conseqüente segregação social, criando-se ambientes periféricos e centrais.

$\mathrm{Na}$ concepção de Lefebvre (2004), a cidade passou ao mesmo tempo a ser produto e produtora, possibilitando assim a acumulação e circulação do capital e gerando um crescimento descontrolado da cidade capitalista a qual, ao mesmo tempo em que anulou as diferenças entre a cidade e o campo, passou fragmentar ambientes dentro da própria cidade, gerando com isso disparidades sociais e o surgimento de periferias, onde a ilegalidade, a marginalidade e a miséria passaram a ser produtos de uma estruturação e um desenvolvimento mal formulados.

Essa urbanização voltada exclusivamente ao capital acabou por influenciar diretamente na consciência de sues habitantes, os quais se acostumaram e acomodaramse diante das desigualdades, aceitando-as como algo natural e necessário para o desenvolvimento ou simplesmente ignorando-as, tanto os que vivem nos centros, pois acreditam estarem em situações privilegiadas, como os que se encontram nas periferias que acabam por assimilar a sua situação acreditando, em suas frustrações, que nada podem fazer para mudar o contexto.

Esta situação somente começou ser constatada e refletida nos últimos anos, mais precisamente na década de 90, a partir da conscientização das crises ambientais que passaram a assolar toda a humanidade, uma vez que a questão da crise ambiental perpassa diretamente pela crise do desenvolvimento urbano. A sociedade industrial chegou ao limite da insustentabilidade, fazendo com que mudanças radicais de âmbito global, envolvendo estruturas econômicas, políticas, tecnológicas e sociais, tornem-se imprescindíveis para a sobrevivência da humanidade.

Assim, surgiu a necessidade de criação de um novo modelo de desenvolvimento que apresentasse políticas de qualidade ambiental, abrangendo tanto a qualidade do meio ambiente natural quanto urbano; passando-se aí então a se falar em desenvolvimento sustentável, estendendo-se assim a um desenvolvimento urbano sustentável, o qual deve atender as necessidades das gerações presentes sem gerar danos às gerações futuras.

De acordo com Carrera (2005, p.7), o “[...] desenvolvimento sustentável não significa somente a conservação dos nossos recursos naturais, mas sobretudo um 
planejamento territorial, das áreas urbanas e rurais, um gerenciamento dos recursos naturais, um controle e estímulo às práticas culturais, à saúde, alimentação e sobretudo qualidade de vida, com distribuição justa de renda per capita."

As expressões desenvolvimento sustentável e sustentabilidade aparecem geralmente na forma de sinônimos, o que efetivamente não corresponde a realidade. A sustentabilidade é a manutenção do status quo ante dos diversos ambientes - natural, artificial, do trabalho, cultural, genético, sendo que “[...] quando usarmos o termo sustentabilidade deve estar implícita a expressão sociedades sustentáveis, pois abrange a integridade dos recursos e processos ambientais naturais, com base em sistemas políticos plurais (democráticos). A expressão deve ser necessariamente compreendida no plural porque, no Instituto Vitae Civilis, bem como num grande universo de ONGs do movimento ambientalista mundial, abraçamos a perspectiva de um mundo ambientalmente sadio, onde as diversidades biológica, cultural, étnica, racial $e$ religiosa são parte integrante dos pressupostos da sustentabilidade.” (BORN, 2003, p.109)

Já o desenvolvimento sustentável pressupõe a evolução, o crescimento em todas as esferas, de forma a suprir as necessidades dos homens sem com isso afetar os recursos ambientais, deixando de comprometer a sustentabilidade destes, bem como “[...] consiste na exploração equilibrada dos recursos naturais, nos limites da satisfação das necessidades do bem-estar da presente geração, assim como de sua conservação no interesse das gerações futura. Requer como seu requisito indispensável, um crescimento econômico que envolva equitativa redistribuição dos resultados do processo produtivo e a erradicação da pobreza, de forma a reduzir as disparidades nos padrões de vida e melhor entendimento da maioria da população.” (SILVA, 2009, p. 26/27)

A expressão desenvolvimento sustentável foi usado pela primeira vez em 1983 pela Primeira Ministra da Noruega e Presidenta da Comissão Mundial sobre o Meio Ambiente e Desenvolvimento, Gro Herlem Bruntland, quando esta, juntamente com uma comissão, propôs que o desenvolvimento econômico fosse integrado à questão ambiental, o que levou a criação do "Relatório Brundtland"; documento este que tornou-se referencial para a Conferência das Nações Unidas sobre Meio Ambiente e Desenvolvimento em 1992 - Rio-92, onde o termo foi vastamente utilizado em diversos documentos, dentre ele a Agenda 21. 
Inúmeros são os conceitos encontrados para a expressão desenvolvimento sustentável, contudo todos chegam a uma mesma concepção, qual seja, de que consiste em usar os recursos naturais respeitando o meio ambiente e os seres vivos que integram o mesmo. Esta utilização responsável perpassa por um desenvolvimento que reconhece os limites dos recursos naturais e concilia o crescimento econômico à preservação da natureza.

A sustentabilidade tem por objetivo uma solidariedade e um compromisso com as futuras gerações; ela transcende ao mundo tecnicista, programado e calculado, que tem por pano de fundo o lucro e atinge uma liberdade da diversidade biológica e cultural, proporcionando uma reconstrução deste mundo.

O desenvolvimento urbano sustentável teve como marco jurídico a Conferência das Nações Unidas sobre o Meio Ambiente, realizada em 1992, da mesma forma que a garantia do direito à cidade, no âmbito nacional, teve seu alicerce no Estatuto da Cidade que teve como objetivo a implementação dos artigos 182 e 183 da Constituição Federal Brasileira, os quais tratam da política urbana, tudo isso visando um direito à cidade como um direito fundamental.

Tais instrumentos jurídicos vêm ao encontro do pensamento de Lefebvre (1999), para quem o direito à cidade é o direito à centralidade, onde deixem de existir a exclusão urbana decorrente de uma organização espacial discriminatória e desordenada. O direito à cidade diz respeito a todos os habitantes enquanto sujeitos que se envolvem em relações sociais dentro do quadro urbano e afirmam a exigência de uma presença ativa e participativa. Da mesma forma o desenvolvimento, na concepção de Veiga (2005) deve ir em direção de uma ecosocioeconomia para ser um garantidor de igualdades e preservação.

\section{Instrumentos da Política Nacional do Meio Ambiente: o Estado como garantidor de meio ambiente sadio e equilibrado}

O Estado Democrático de Direito Ambiental pressupõem a interação dos indivíduos na concretização de políticas públicas que visem resguardar os bens naturais, e, dentro desta concepção, a Declaração do Rio e a Agenda 21 traçaram objetivos de criação de políticas públicas que incentivam a promoção de um desenvolvimento 
sustentável, as quais partem de uma participação ativa da sociedade não só no âmbito de informações como também de processos decisórios; bem como aborda a questão das diferenças sociais como uma das causas de danos ambientais, buscando a implantação de políticas de erradicação à pobreza.

O Brasil, seguindo tais orientações traz tanto na Lei $n^{\circ} 6.938 / 81$, quanto em sua Constituição a responsabilidade tanto da sociedade quanto do Poder Público de proteger e preservar o meio ambiente ecologicamente equilibrados visando uma qualidade de vida não apenas para as gerações presentes quanto para as futuras. Com base nestes ditames, tais legislações determinaram o dever do Estado de implementar políticas de proteção ambiental, o que resultou na criação da Política Nacional do Meio Ambiente a qual “[...] necessita de uma série de ações a cargo do Poder Público, para ter garantida a sua efetividade, implementando-se de fato o princípio do desenvolvimento sustentável, [...]” (GRAZIERA, 2011, p.77).

No artigo $2^{\circ}$ da Lei $n^{\circ}$ 6.938/81, além de trazer o objetivo das políticas ambientais, discorre sobre os princípios que devem ser atendidos pela mesma, quais sejam: “[...] A Política Nacional do Meio Ambiente tem por objetivo a preservação, melhoria e recuperação da qualidade ambiental propícia à vida, visando assegurar, no País, condições ao desenvolvimento socioeconômico, aos interesses da segurança nacional e à proteção da dignidade da vida humana, [...]”.

Visando o cumprimento das determinações da Política Nacional do Meio Ambiente, no que tange ao dever do Estado de proteção dos processos ecológicos essenciais pode-se citar a Lei $n^{\circ} 9.985 / 00$, a qual instituiu o Sistema Nacional de Unidades de Conservação que tinha como objetivo a preservação das espécies, seu habitat e o ecossistema, determinando que as unidades de conservação elaborassem um Plano de Manejo dos recursos naturais, o que reflete diretamente do contexto atual de urbanização, uma vez que é esta uma das principais responsáveis pelos danos causados as espécies, já que em nome da construção de cidades, o habitat natural das espécies está sendo destruído.

Quanto à proteção da diversidade e da integridade do patrimônio genético, o que está expresso em mais de um dos princípios acima elencados, visto que objetiva a indivisibilidade do bem ambiental, foi editada a Lei $\mathrm{n}^{\mathrm{o}} 11.105 / 05$, onde foi instituída “[...] uma estrutura de competências administrativas composta por três instâncias 
específicas: o Conselho Nacional de Biossegurança (CNBS); a Comissão Técnica Nacional de Biossegurança (CTNBio), e os órgãos e entidades de registro de fiscalização.” (Canotilho, 2011, p. 259)

O Estado também recebeu o dever de definir em todas as suas unidades federativas os espaços territoriais e seus componentes que receberiam uma proteção especial. Neste sentido, antes mesmo da Constituição Federal, já existia a Lei $\mathrm{n}^{\mathbf{o}}$ 4.771/65, que já trazia proteção especial a determinados espaços territoriais, os quais eram denominados de ares de preservação permanente; posteriormente à mesma, e agora já dentro dos ditames constitucionais, e visando regulamentar alguns dos artigos desta, foi editada a Lei $\mathrm{n}^{\circ}$ 9.985/00, a qual instituiu o Sistema Nacional de Unidades de Conservação da Natureza (SNUC). A referida lei dividiu as unidades de conservação em dois grupos, quais sejam: as Unidades de Proteção Integral e as Unidades de Uso Sustentável. Agregado a estas regulamentações, a Lei n ${ }^{\circ} 9.985 / 00$ ainda institui a Reserva da Biosfera, sendo que atualmente no Brasil existem sete destas reservas.

A Lei da Política Nacional de Meio Ambiente já determinava a realização de estudo de impacto ambiental (EPIA), o que foi ratificado pela Constituição de 1988, qual deve, obrigatoriamente, ser realizado antes da instalação de qualquer obra ou atividade potencialmente causadora de dano ambiental. Para estabelecer os critérios que o referido estudo deve seguir, foi editado o Decreto $\mathrm{n}^{\circ} 88.351 / 83$, o qual criou o Conselho Nacional do Meio Ambiente (COBAMA), o qual determinou que uma vez concluído o estudo de impacto ambiental, que terá que ser realizado por um profissional habilitado, deverá ser redigido um documento que traga as conclusões deste, o qual deverá ficar liberado para informação de qualquer pessoa da sociedade, especialmente aqueles que podem ser possíveis lesados pela degradação ambiental decorrente da atividade analisada.

Por derradeiro, e não menos importante, temos a Política Nacional de Educação Ambiental, a qual busca, através da educação ambiental, capacitar a sociedade, em todos os âmbitos, para defender o meio ambiente; em outras palavras, capacitar os indivíduos para exercerem a cidadania ambiental com responsabilidade e comprometimento. Assim, em cumprimento a determinação do inciso X da lei que trata das Políticas Ambientais, foi editada a Lei ${ }^{\circ}$ 9.795/99, conhecida como a Lei da Educação Ambiental, pela qual o processo de educação ambiental deve estar presente 
em todos os níveis de ensino, seja na educação formal quanto na informal, tornando a educação ambiental parte da educação nacional.

A referida Lei da Educação Ambiental tem como princípios básicos “[...] o enfoque democrático e participativo, enfatizando o respeito ao pluralismo de ideias e concepções e o reconhecimento da diversidade individual e cultural. [...]” (Canotilho, 2011, p. 281); entretanto, o ponto culminante da mesma é o fortalecimento da cidadania.

Toda a fundamentação legal que dá amparo e suporte para que o Estado Democrático de Direito Ambiental venha a ter efetividade, especialmente com a concepção de um Estado onde a participação democrática, sobretudo nas questões ambientais, não é suficiente por si só para garantir um desenvolvimento sustentável. É imprescindível que todos os atores envolvidos - sociedade e Estado - nesta nova concepção de cidadania estejam cientes da realidade fática das questões ambientais, de maneira especial da crise que aflige o meio ambiente; bem como tenham conhecimento dos reais conceitos de desenvolvimento e de sustentabilidade, pois sem isso não é possível a efetivação dos preceitos constitucionais e legais de proteção ambiental, o que nada mais é do que o exercício da cidadania na busca da garantia de um meio ambiente sustentável como caracterizador de direitos humanos.

\section{CONSIDERAÇÕES FINAIS}

O meio ambiente urbano saudável e equilibrado é de titularidade de todos os indivíduos, e devidos a cada um, os quais tem legitimidade para exigirem a efetividade dos mesmos com base em sua natureza ética, através de instrumentos jurídicos e políticas concretas em um contexto universal; passando assim a gerarem obrigações aos próprios indivíduos e ao Estado, os quais são atores principais na garantia da efetividade dos direitos ambientais.

Destarte, diante de todas as leituras e reflexões que embasaram o presente texto foi possível constatar que o reconhecimento do direito ao ambiente como um dos direitos fundamentais da pessoa humana é assim, a possibilidade de construir uma sociedade que tenha como base a democracia, a participação e a solidariedade voltada para um novo contexto socioambiental, na relação do homem com o meio ambiente, (re)significando a importância do meio ambiente ecologicamente equilibrado para a 


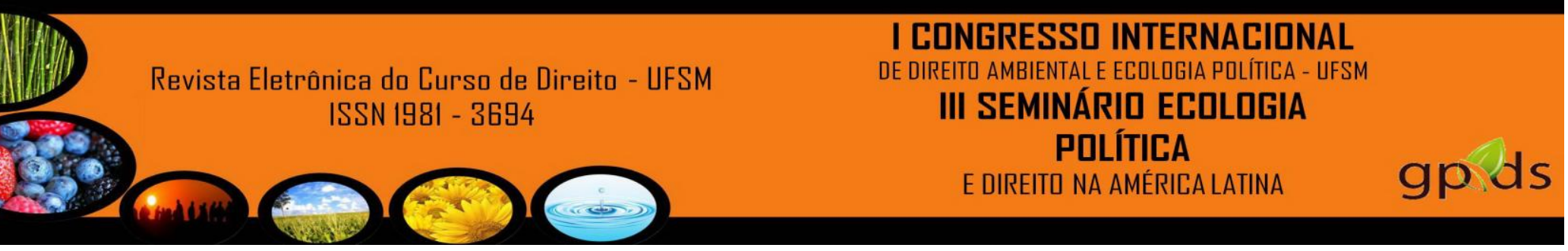

qualidade de vida, evitando assim os riscos ambientais a que esta vem sendo exposta.

Não bastam legislações positivas garantidoras, é necessária a conscientização da sociedade de que somos agentes, sujeitos capazes, em interação no planeta, naquilo que fazemos e naquilo que deixarmos de fazer, em aspectos positivos ou negativos, definindo a qualidade ambiental, e por consequência, qualidade de vida das gerações futuras. É esta sociedade a responsável por realizar todos os esforços para garantir as condições mínimas de sobrevivência e de respeito aos direitos humanos das gerações presentes e futuras.

Esta concepção estende-se ao meio ambiente urbano, que através de um desenvolvimento urbano sustentável visa garantir o direito à cidade mediante a (re)construção de uma unidade espaço-temporal, reconduzindo à unidade aquilo que foi fragmentado e pulverizado pela urbanização capitalista. Da mesma forma é necessária a conscientização da sociedade de que somos agentes, sujeitos capazes, em interação no planeta, naquilo que fazemos e naquilo que deixarmos de fazer, em aspectos positivos ou negativos, definindo a qualidade ambiental, e por conseqüência, qualidade de vida das gerações futuras.

\section{REFERÊNCIAS BIBLIOGRÁFICAS}

BORN, Rubens Harry. Articulação do capital social pelo movimento ambientalista para a sustentabilidade do desenvolvimento no Brasil, in: Trigueiro. André (org.), Meio Ambiente do Século 21. Rio de Janeiro: Sextante, 2003.

CARRERA, Francisco. Cidade Sustentável: Utopia ou Realidade. Rio de Janeiro: Lumen Juris, 2005.

LEFEBVRE, Henri. A Revolução Urbana. Belo Horizonte: UFMG, 1999.

. O Direito à Cidade. São Paulo: Centauro, 2004.

SARMENTO, Daniel. A ponderação de interesses na Constituição Federal. Rio de Janeiro: Lumen Juris, 2002. 


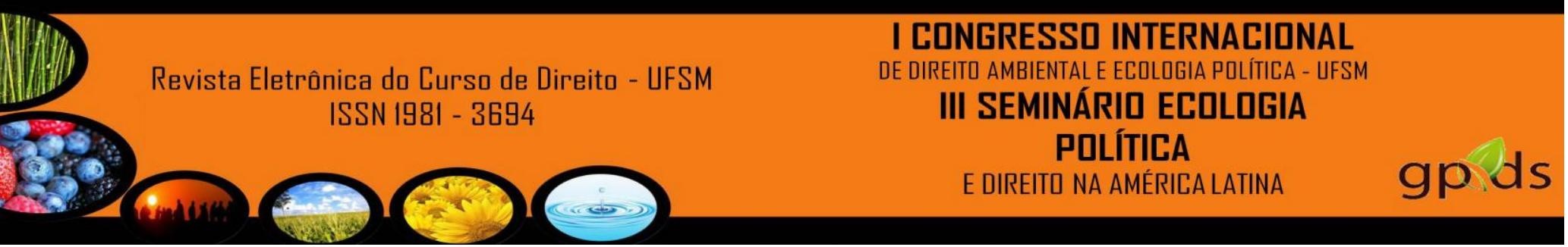

SILVA, José Afonso da. Direito Ambiental Constitucional. 7ed. São Paulo: Malheiros, 2009.

VEIGA, José Eli da. Desenvolvimento Sustentável: o desafio do século XXI. Rio de Janeiro: Garamond, 2005. 